\title{
Presence and activation of pro- inflammatory macrophages are associated with CRYAB expression in vitro and after peripheral nerve injury
}

Erin-Mai F. Lim', Vahid Hoghooghi ${ }^{1}$, Kathleen M. Hagen ${ }^{1}$, Kunal Kapoor ${ }^{2}$, Ariana Frederick ${ }^{2}$, Trisha M. Finlay ${ }^{1}$ and Shalina S. Ousman ${ }^{2,3^{*}}$ (D)

\begin{abstract}
Background: Inflammation constitutes both positive and negative aspects to recovery following peripheral nerve injury. Following damage to the peripheral nervous system (PNS), immune cells such as macrophages play a beneficial role in creating a supportive environment for regrowing axons by phagocytosing myelin and axonal debris. However, a prolonged inflammatory response after peripheral nerve injury has been implicated in the pathogenesis of negative symptoms like neuropathic pain. Therefore, the post-injury inflammation must be carefully controlled to prevent secondary damage while allowing for regeneration. CRYAB (also known as alphaB-crystallin/ HSPB5) is a small heat shock protein that has many protective functions including an immunomodulatory role in mouse models of multiple sclerosis, spinal cord injury, and stroke. Because its expression wanes and rebounds in the early and late periods respectively after PNS damage, and CRYAB null mice with sciatic nerve crush injury display symptoms of pain, we investigated whether CRYAB is involved in the immune response following PNS injury.
\end{abstract}

Methods: Sciatic nerve crush injuries were performed in age-matched Cryab knockout (Cryab ${ }^{-1-}$ ) and wildtype (WT) female mice. Nerve segments distal to the injury site were processed by immunohistochemistry for macrophages and myelin while protein lysates of the nerves were analyzed for cytokines and chemokines using Luminex and enzyme-linked immunosorbent assay (ELISA). Peritoneal macrophages from the two genotypes were also cultured and polarized into pro-inflammatory or anti-inflammatory phenotypes where their supernatants were analyzed for cytokines and chemokines by ELISA and protein lysates for macrophage antigen presenting markers using western blotting.

(Continued on next page)

\footnotetext{
* Correspondence: sousman@ucalgary.ca

${ }^{2}$ Department of Clinical Neurosciences, Hotchkiss Brain Institute, University of

Calgary, 3330 Hospital Drive N.W., Heritage Medical Research Building,

Calgary, Alberta T2N 4N1, Canada

${ }^{3}$ Department of Cell Biology \& Anatomy, Hotchkiss Brain Institute, University

of Calgary, 3330 Hospital Drive N.W., Heritage Medical Research Building,

Calgary, Alberta T2N 4N1, Canada

Full list of author information is available at the end of the article
}

C C The Author(s). 2021 Open Access This article is licensed under a Creative Commons Attribution 4.0 International License, which permits use, sharing, adaptation, distribution and reproduction in any medium or format, as long as you give appropriate credit to the original author(s) and the source, provide a link to the Creative Commons licence, and indicate if changes were made. The images or other third party material in this article are included in the article's Creative Commons licence, unless indicated otherwise in a credit line to the material. If material is not included in the article's Creative Commons licence and your intended use is not permitted by statutory regulation or exceeds the permitted use, you will need to obtain permission directly from the copyright holder. To view a copy of this licence, visit http://creativecommons.org/licenses/by/4.0/ The Creative Commons Public Domain Dedication waiver (http://creativecommons.org/publicdomain/zero/1.0/) applies to the data made available in this article, unless otherwise stated in a credit line to the data. 
(Continued from previous page)

Results: We report that (1) more pro-inflammatory CD16/32 $2^{+}$macrophages are present in the nerves of Cryab ${ }^{-1-}$ mice at days 14 and 21 after sciatic nerve crush-injury compared to WT counterparts, and (2) CRYAB has an immunosuppressive effect on cytokine secretion [interleukin (IL)- $\beta, \mathrm{IL}-6, \mathrm{IL}-12 \mathrm{p} 40$, tumor necrosis factor (TNF)- $\mathrm{a}$ ] from pro-inflammatory macrophages in vitro.

Conclusions: CRYAB may play a role in curbing the potentially detrimental pro-inflammatory macrophage response during the late stages of peripheral nerve regeneration.

Keywords: Peripheral nervous system, Peripheral nerve injury, Macrophages, Pro-inflammatory, CRYAB, AlphaB-crystallin, Cytokines, Chemokines

\section{Background}

Hematogenously-derived macrophages are essential for successful regeneration of damaged peripheral nervous system (PNS) axons. Due to the secretion of cytokines and chemokines such as monocyte chemoattractant protein-1 (MCP-1), tumor necrosis factor alpha (TNF- $\alpha$ ), interleukin (IL) 1 beta (IL-1 $\beta$ ), interleukin 6 (IL-6), and leukemia inhibitory factor (LIF) by de-differentiated Schwann cells following peripheral nerve injury, monocytes are recruited from the blood compartment into the distal segment of damaged axons within 2-3 days post-injury [1-4]. These monocytes differentiate into macrophages that produce additional TNF- $\alpha$, IL- 6 , IL- $1-\alpha$, and IL- $1 \beta$ that contribute to further infiltration of blood-derived monocytes [3-7]. The mature macrophages, along with de-differentiated Schwann cells and proliferating resident macrophages, play a central role in creating a supportive environment for regenerating axons because they secrete neurotrophins and phagocytose and clear axonal and myelin debris that contain inhibitors against neurite growth. Indeed, their delayed recruitment or depletion results in reduced myelin debris clearance, loss of neurotrophin synthesis, and compromised axonal regeneration and functional recovery [1, 8-10]. However, a prolonged inflammatory response has been implicated in the pathogenesis of negative symptoms after peripheral nerve injury or other nerve diseases [11, 12]. For example, prolonged presence of IL-1 $\beta$ and TNF- $\alpha$ can promote cell death and neurodegeneration as well as mediate neuroma formation by stimulating fibroblast proliferation [7, 12]. Further, macrophages have a crucial role in the development of peripheral nerve injury-induced neuropathic pain [13-18]. It is thus important to understand how the beneficial properties of macrophages can be harnessed while reducing their pathological functions after peripheral nerve injury.

Macrophages are divided into different phenotypes according to their function or stimulation. In terms of function, these immune cells can be broadly classified as proinflammatory (generally called M1) or anti-inflammatory (M2). Anti-inflammatory phenotypes can be further divided into subpopulations due to their diverse modes of stimulation: M2a (activated by IL-4 and IL-13), M2b (activated by immune complexes in combination with IL-1 $\beta$ and lipopolysaccharide (LPS)), and M2c (activated by IL-10, transforming growth factor beta (TGF- $\beta$ ), or glucocorticoids) [19]. It is now recognized that the phenotype of macrophages is much more complex than M1 and M2 and that the cells exist as a continuum of states that shift back and forth depending on the type of stimuli present in the environment. Indeed, this has also been shown for peripheral nerves [20,21]. We will thus refer to macrophages as either pro- or anti-inflammatory. What is incompletely known are the factors that control the various functional states of macrophages in peripheral nerves after damage.

CRYAB (also known as HSPB5 or alphaB-crystallin) is a small heat shock protein that has been shown to possess a number of protective functions including chaperoning [2224], pro-survival [25-28], anti-inflammatory [29], remyelinating [30], and anti-neurotoxic [31] abilities. With respect to its immunomodulatory role, treatment with recombinant human CRYAB was demonstrated to dampen the inflammatory response in injured spinal cord [32] while mice that are null for the heat shock protein display enhanced $\mathrm{T}$ cell and macrophage activation in experimental allergic encephalomyelitis [33-35] and stroke [36, 37]. Because of its expression in PNS axons and Schwann cells [30, 38-40], altered levels post-PNS damage [30] (reduced and then increased) and enhanced symptoms of pain in Cryab ${ }^{-1-}$ mice with sciatic nerve crush injury [30], we investigated whether the small heat shock protein is involved in macrophage infiltration and phenotype following peripheral nerve injury. We found that the presence of macrophages is prolonged in sciatic nerves after damage in Cryab null mice and that these immune cells were primarily of a pro-inflammatory nature. Further, in vitro experiments with LPS-activated peritoneal macrophages suggest that the heat shock protein may contribute to inhibiting proinflammatory cytokine production by macrophages.

\section{Methods}

Mice

Cryab-null $\left(\mathrm{Cryab}^{-/-}\right)$mice were developed at the $\mathrm{Na}$ tional Institutes of Health National Eye Institute [41]. The animals were generated from embryonic stem cells with a 129S4/SvJae background and maintained on a 
129S6/SvEvTac X 129S4/SvJae background. Cryab $^{-/-}$ mice are viable and fertile. At approximately 40 weeks of age, these animals display a curved spinal cord and degeneration of muscles [41]. We studied these animals between 8 and 12 weeks of age to ensure that the aging characteristics did not confound our results. This was validated by performing analyses on age-matched uninjured 129S6/SvEvTac wildtype (WT) and $\mathrm{Cryab}^{-/-}$mice before injury to confirm equivalent baseline properties. Colonies of WT and Cryab ${ }^{-/-}$mice were bred and maintained in our animal facility where they had access to food and water ad libitum. All procedures were carried out in accordance with guidelines of the Canadian Council of Animal Care and had received approval by the University of Calgary Animal Resources and Ethics Committee.

\section{Surgery}

Eight to 12-week-old female WT and $\mathrm{Cryab}^{-/-}$mice were anesthetized with a 3:1 ketamine/xylazine $(200 \mathrm{mg} /$ $\mathrm{kg}: 10 \mathrm{mg} / \mathrm{kg}$ ) mixture by intraperitoneal injection. An incision was made through the skin below the hip, and the muscle was blunt dissected using fine surgical scissors and forceps to expose the right sciatic nerve at midthigh level. The nerve was crushed $0.5 \mathrm{~cm}$ above the region where it splits into the sural, common peroneal, and tibial branches. The sciatic nerve was crushed using 5.0 fine forceps for $30 \mathrm{~s}$; after which, the forceps were rotated $90^{\circ}$, and the same area was crushed for an additional $30 \mathrm{~s}$ to ensure that the majority of axons were crushed [30]. Animals were allowed to recover on a heated pad, and their sciatic nerves were harvested at 1 , $3,5,7,14,21$, or 28 days post-injury.

\section{Immunohistochemistry}

Naïve and post-crushed mice were euthanized with carbon dioxide. A 5-mm segment of the sciatic nerve starting at $3 \mathrm{~mm}$ from the sciatic notch area was removed from naive animals while a $5-\mathrm{mm}$ portion of the nerve $3 \mathrm{~mm}$ distal from the crush site was obtained from injured animals. Nerves were fixed in Zamboni's fixative for $2 \mathrm{~h}$ at room temperature, cryoprotected in $30 \%$ sucrose solution for $48 \mathrm{~h}$, embedded into optimum cutting temperature compound, and frozen. Ten-micrometer thick crosssections were obtained where sectioning was initiated at the end of the dissected nerve segment that was $3 \mathrm{~mm}$ distal to the crush site. Sections were then blocked with phosphate-buffered saline containing $0.1-0.3 \%$ Triton X100 and $5-10 \%$ normal goat serum for $1 \mathrm{~h}$ at room temperature or 3 days at $4{ }^{\circ} \mathrm{C}$ (iNOS and Arg1). The tissues were incubated overnight at $4{ }^{\circ} \mathrm{C}$ with rabbit antiIba1 (Wako Chemicals, 019-1974, 1:200) or goat anti-Iba1 (Novus Biologicals, NB100-1028, 1:100), rat anti-mouse CD16/32 (BD Biosciences, 553842, 1:500), goat anti- mouse CD206 (Santa Cruz Biotechnologies, sc-34577, 1: 500), chicken anti-P0 (Abcam, ab39375, 1:500), rabbit anti-CD68 (Cell Signaling, 97778, 1:100), rabbit antiarginase 1 (Cell Signaling, 93668, 1:50), rabbit anti-iNOS (BD Transduction Laboratories, 1:100; gift from Dr. Samuel David, McGill University), and DAPI (Invitrogen, D3571, 1:2000). Bound antibody was detected using the Invitrogen secondary antibodies, anti-rabbit 488 (A11008), anti-rabbit 594 (A21207), anti-rat 488 (A11006), or antigoat 488 (A11055) at 1:200 or 1:500.

\section{Immunohistochemistry quantification}

Three to four cross-sections that were $50 \mu \mathrm{m}$ apart from each other were obtained from every animal in both genotypes. Following immunostaining, the whole crosssectional-stained area of the sciatic nerve was obtained at $\times 20$ magnification with an Olympus Slide Scanner microscope. The number of $\mathrm{Iba}^{+} \mathrm{DAPI}^{+}, \mathrm{CD} 206^{+} \mathrm{Iba}^{+}$ $\mathrm{DAPI}^{+}, \mathrm{CD}_{16} / 32^{+} \mathrm{Iba}^{+} \mathrm{DAPI}^{+}$, and $\mathrm{PO}^{+} \mathrm{Iba}^{+} \mathrm{DAPI}^{+}$ profiles was quantified in the entire sciatic nerve crosssectional area using Olympus cellSens. Each z-series (depth of $\mathrm{x} \mu \mathrm{m}$ ) was processed into a single focused image using extended focal imaging. A region of interest was drawn around the sections and a minimum object size of 150 pixels was defined for measurements. A manual global intensity threshold was determined on random images for each of the three channels, and all images were segmented using these same thresholds. The engulfing of myelin debris by macrophages was identified by the colocalization of overlapping pixels in the segmented images. Object counts, areas, and area fractions were obtained for each group.

\section{Luminex}

A 5-mm segment of the sciatic nerve starting from the sciatic notch area was removed from naïve animals while a 5 - $\mathrm{mm}$ portion of the nerve $3 \mathrm{~mm}$ distal from the crush site was obtained from injured animals at various time points post-crush $(1,3,5,7,14,21$, and 28 days) from WT and Cryab ${ }^{-/-}$mice ( $n=3-4$ /group) and frozen. The nerves were then homogenized in a solution containing $50 \mathrm{mM}$ Tris-hydrochloride (Tris-HCL) pH 7.4, 1\% NP$40, \quad 10 \%$ glycerol, $1 \mathrm{mM}$ ethylenediaminetetraacetic (EDTA), $1 \mathrm{mM}$ sodium vanadate $\left(\mathrm{Na}_{3} \mathrm{VO}_{4}\right), 1 \mathrm{mM}$ sodium fluoride (NaF), $1 \mathrm{mM}$ dithiothreitol (DTT), 4.5 $\mathrm{mM}$ sodium pyrophosphate, $10 \mathrm{mM} \beta$-glycerophosphate, and a protease inhibitor cocktail tablet (Roche Diagnostics). The supernatants were collected after centrifugation at $14,000 \mathrm{rpm}$ at $4{ }^{\circ} \mathrm{C}$ for $20 \mathrm{~min}$, and protein content was determined with a spectrophotometer using absorption at $570 \mathrm{~nm}$. All samples were diluted to $667 \mu \mathrm{g} / \mathrm{mL}$ to ensure equal amounts of protein. The protein levels of 31 cytokines and chemokines were assayed using Eve Technologies' (Calgary, AB, Canada) Mouse 
Cytokine Array/Chemokine Array 31-Plex laser bead technology (MD31) and results analyzed using Bead Analyzer (Bio-Plex 200). The array factors were as follows: eotaxin, granulocyte-colony stimulating factor (GCSF), granulocyte-macrophage colony-stimulating factor (GM-CSF), IL-1 $\alpha$, IL-1 $\beta$, IL-2, IL-3, IL-4, IL-5, IL-6, IL7, IL-9, IL-10, IL-12p40, IL-12p70, IL-13, IL-15, IL-17A, interferon gamma (IFN)- $\gamma$, interferon gamma-induced protein 10 (IP-10), keratinocyte chemoattractant (KC), LIF, lipopolysaccharide-inducible CXC chemokine (LIX), macrophage chemotactic protein-1, macrophage colonystimulating factor (M-CSF), monokine induced by gamma interferon (MIG), macrophage inflammatory protein-1 (MIP) $\alpha$, MIP-1 $\beta$, MIP-2, regulated on activation normal $\mathrm{T}$ cell expressed and secreted (RANTES), TNF- $\alpha$, vascular endothelial growth factor (VEGF).

\section{Peritoneal macrophage preparation and polarization}

Eight to 12-week-old female WT and Cryab ${ }^{-/}$mice were injected intraperitoneally with $3 \mathrm{~mL}$ of thioglycollate broth (BD Biosciences). After 3 days, the mice were sacrificed and injected intraperitoneally with $5 \mathrm{~mL}$ icecold Dulbecco's modified eagle media (DMEM) (Invitrogen). The DMEM solution within the peritoneal cavity was collected and centrifuged at $1400 \mathrm{rpm}$ for $10 \mathrm{~min}$ at $4{ }^{\circ} \mathrm{C}$. The pellet was resuspended in media consisting of $1 \%$ pyruvate, $1 \%$ glutamine, and $1 \%$ penicillin streptomycin in DMEM. Cells were plated at a concentration of $1,000,000$ cells $/ \mathrm{mL}$ at $37^{\circ} \mathrm{C}$ in $5 \% \mathrm{CO}_{2}$. After 4 days, cells were stimulated with or without $100 \mathrm{ng} / \mathrm{mL}$ LPS, $100 \mathrm{ng} /$ $\mathrm{mL}$ LPS $+100 \mathrm{U} / \mathrm{mL}$ recombinant mouse $(\mathrm{rm})-\mathrm{IFN}-\gamma$ (Gibco, PMC4031), or $10 \mathrm{ng} / \mathrm{mL}$ rm-IL-4 (Peprotech, 214-14) + $10 \mathrm{ng} / \mathrm{mL}$ rm-IL-13 (Peprotech, 210-13), in the presence or absence of $2 \mu \mathrm{g} / \mathrm{mL}$ CRYAB peptide (7392) [35] (Stanford University Pan Facility, Stanford, California, USA) for 24 or $48 \mathrm{~h}$.

\section{ELISA}

Supernatants from cultured WT and $\mathrm{Cryab}^{-/-}$peritoneal macrophages were analyzed for levels of IL-6 (BD Biosciences, 555240), IL-1 $\beta$ (BD Biosciences, 559603), IL-12p40 (BD Biosciences, 555165), and TNF- $\alpha$ (R\&D Systems, DY410) by ELISA according to the manufacturer's instructions.

\section{ELISA quantification}

The optical density of each well was quantified using the MMP6 software. Briefly, protein content was determined with a spectrophotometer using absorption at $450 \mathrm{~nm}$ to analyze the protein concentration as a function of the optical density. Protein concentrations were then calculated using the corresponding standard curves.

\section{RT-PCR}

Two hundred nanograms of RNA was used for reverse transcription into cDNA. The Qiagen QuantiTect Reverse Transcription kit was used, which consists of a gDNA elimination step followed by reverse transcription. After completion of reverse transcription, $65 \mu \mathrm{L}$ of RNase/DNase free water was added to each sample. qPCR was performed in triplicates using the QuantiFast SYBR Green PCR kit with QuantiTect Primer Assay primers for the following genes: GAPDH, Mm_Gapdh 3_SG; IL-10, Mm_Il10_1_SG; IL-12, Mm_Il12a_1_SG; iNOS, Mm_LOC673161_1_SG; Arg1, Mm_Arg1_1_SG.

\section{Western blotting}

Total protein was isolated from cultured peritoneal macrophages in a solution containing $50 \mathrm{mM}$ Tris-HCL pH 7.4, $1 \%$ NP-40, $10 \%$ glycerol, $1 \mathrm{mM}$ EDTA, $1 \mathrm{mM} \mathrm{Na} \mathrm{VO}_{4}, 1 \mathrm{mM}$ $\mathrm{NaF}, 1 \mathrm{mM}$ DTT, $4.5 \mathrm{mM}$ sodium pyrophosphate, $10 \mathrm{mM} \beta$ glycerophosphate, and a protease inhibitor cocktail tablet (Roche Diagnostics). The supernatants were collected after centrifugation at $14,000 \mathrm{rpm}$ at $4{ }^{\circ} \mathrm{C}$ for $20 \mathrm{~min}$, and protein content determined with a spectrophotometer using absorption at $570 \mathrm{~nm}$. Forty micrograms of protein was suspended in two volumes of double-strength sodium dodecyl sulfate (SDS) sample buffer (Bio-Rad Laboratories) and subjected to 6-15\% SDS-polyacrylamide gel electrophoresis. Proteins were then transferred to polyvinylidene fluoride membranes that were blocked with $10 \%$ non-fat dried milk in Tris-HClbuffered saline containing $0.05 \%$ Tween-20. Membranes were immunoblotted overnight at $4{ }^{\circ} \mathrm{C}$ with the following primary antibodies: rabbit anti-CD80 (Abcam, ab53003, 1: 2000), rabbit anti-CD86 (Abcam, ab53004, 1:2000), and rabbit anti-actin (Sigma, A2006, 1:1000). Bound primary antibodies were visualized using horseradish peroxidaseconjugated anti-rabbit IgG (GE Healthcare, 1:5000) followed by chemiluminescence detection using an ECL kit (Pierce).

\section{Western blot densitometric quantification}

Western blot bands were quantified using the ImageJ software. Briefly, arbitrary pixel units were obtained for the optical density (OD) of an area around each band, and a ratio of OD:area was calculated. The OD:area values for a protein of interest were then normalized to the corresponding actin OD:area numbers.

\section{Statistical analysis}

Statistical analysis was performed using Graphpad Prism 6. Data are presented as means \pm sem. Data was analyzed using two-tailed independent Student's $t$-test to detect between-group differences, and two-tailed paired $t$-test to detect differences before and after treatment with CRYAB peptide; $p<0.05$ was considered significant. 


\section{Results}

$\mathrm{Cryab}^{-/-}$mice display prolonged presence of macrophages in injured distal sciatic nerves

CRYAB has been shown to possess immunosuppressive properties in stroke and a model of multiple sclerosis. Because prolonged presence of macrophages and their secretory products can contribute to pain hypersensitivity in damaged peripheral nerves [13-18], we asked whether the enhanced sensation to painful stimuli observed in $\mathrm{Cryab}^{-/-}$mice with sciatic nerve crush injury [30] may be related to enhanced influx and/or presence of macrophages. As such, we quantified the number of $\mathrm{Iba}^{+} \mathrm{DAPI}^{+}$macrophages in uninjured sciatic nerve at $1,3,5,7,14,21$, and 28 days after crush damage in WT and $\mathrm{Cryab}^{-/-}$mice. Immunofluorescence labeling revealed no difference in $\mathrm{Iba}^{+}{ }^{+} \mathrm{DAPI}^{+}$counts between uninjured WT $(58.83 \pm 9.96)$ and Cryab $^{-/-}(74.40 \pm 13.75)$ nerves (Fig. 1a). At $3 \mathrm{~mm}$ distal to a crush injury, there was a marked, expected increase in the number of Iba $1^{+}$ $\mathrm{DAPI}^{+}$macrophages at 3,5 , and 7 days post-damage in WT sciatic nerves relative to uninjured nerves (Fig. 1a). At these time points, Cryab ${ }^{-/-}$nerves also showed an increase in the number of $\mathrm{Iba}^{+}$macrophages similar to that as the WT cohort except at 3 days post-crush where fewer $\mathrm{Iba}^{+} \mathrm{DAPI}^{+}$profiles were observed. At later time points post-damage in WT mice (14 days and onwards), the number of $\mathrm{Iba}^{+} \mathrm{DAPI}^{+}$macrophages decreased precipitously and returned to baseline status by day 21 . In injured $\mathrm{Cryab}^{-/-}$animals, however, the number of $\mathrm{Iba}^{+}$ $\mathrm{DAPI}^{+}$macrophages remained elevated at 14 [193.00 \pm $22.05\left(\mathrm{Cryab}^{-/-}\right)$vs $138.40 \pm 9.45$ (WT)] and 21 days $\left[185.40 \pm 60.94\left(\mathrm{Cryab}^{-/-}\right)\right.$vs $39.80 \pm 8.69$ (WT)] postinjury compared to WT mice, and only decreased back to baseline at 28 days post-damage (Fig. 1a). The null animals thus displayed a prolonged presence of macrophages following PNS crush damage.

The similar number of macrophages early after injury (5 and 7 days) between the WT and Cryab ${ }^{-/-}$animals (Fig. 1a) suggested that the recruitment of monocytes was not impacted by the small heat shock protein. Indeed, when nerve protein lysates were assayed for the presence of cytokines (IL-6, IL-1 $\beta$, and TNF- $\alpha$ ) and chemokines (MCP-1) known to mediate infiltration of monocytes into damaged peripheral nerves [10, 15, 42], we found no overall difference in their levels between WT and Cryab ${ }^{-/-}$mice at days 1-7 post-injury; lower levels of TNF- $\alpha$ were detected at days 1 and 5 in damaged $\mathrm{Cryab}^{-1-}$ nerves (Fig. $1 \mathrm{~b}-\mathrm{e}$ ). At later time points post-injury, the levels of IL- 6 , IL- $1 \beta$, TNF- $\alpha$, and MCP-1 were also indistinguishable between WT and Cryab null nerves indicating that although the presence of macrophages was prolonged in $\mathrm{Cryab}^{-/-}$mice, the cytokine/ chemokine content within the nerve was similar to that of WT mice. Other cytokines and chemokines on the luminex array displayed no overall difference (eotaxin, G-CSF, IL-1 $\alpha$, IL-9, IP-10, KC, LIF, MIG, MIP-1 $\alpha$, MIP$1 \beta$, MIP-2) or were not detectable (GM-CSF, IFN- $\gamma$, IL2, IL-3, IL-4, IL-5, IL-7, IL-10, IL-12p40, IL-12p70, IL13, IL-15, IL-17A, LIX, RANTES, VEGF) (data not shown).

\section{Myelin clearance after nerve injury is not impacted by CRYAB}

To investigate if aberrations in Wallerian degeneration processes may account for the sustained presence of $\mathrm{Iba}^{+}$cells in damaged $\mathrm{Cryab^{-/- }}$ sciatic nerves, we monitored for macrophage phagocytosis by measuring for the number of $\mathrm{Iba}^{+} \mathrm{DAPI}^{+}$profiles that were protein zero positive $\left(\mathrm{PO}^{+}\right)$. We also measured for total myelin and the amount of P0 staining outside of $\mathrm{Iba}^{+} \mathrm{DAPI}^{+}$cells (Fig. 2). First, as expected after injury in WT animals, the amount of total stained myelin increased in the nerves of WT animals at days 3 and 5 post-damage likely because of unraveling and breakdown of the myelin sheath. This was followed by a decrease at days 7 and 14 after nerve crush that is probably due to myelin debris phagocytosis and digestion by macrophages and Schwann cells. The myelin level then rebounded at day 21 when re-myelination had likely initiated (Fig. 2 a, b). When the amount of total myelin was measured in the injured $\mathrm{Cryab}^{-/-}$mice, there was no difference relative to the WT controls at any of the time points post-injury, except in the naïve situation where the null animals displayed a higher amount of P0 staining. A similar result was seen when the number of $\mathrm{Iba}^{+} \mathrm{DAPI}^{+} \mathrm{P}^{+}$profiles (Fig. 2 a, c) or amount of myelin outside of $\mathrm{Iba}^{+} \mathrm{DAPI}^{+}$ profiles (Fig. 2 a, d) was measured in WT and Cryab ${ }^{-1-}$ animals. That is, no differences were evident between the two genotypes at any timepoint after damage in the number of $\mathrm{Iba}^{+} \mathrm{DAPI}^{+}$cells that co-stained for $\mathrm{P} 0$ or in the amount of $\mathrm{P} 0$ profiles outside of $\mathrm{Iba}^{+} \mathrm{DAPI}^{+}$cells. This suggests that the phagocytic ability of macrophages is not dependent on CRYAB.

\section{The increased number of macrophages in injured $\mathrm{Cryab}^{-/-}$sciatic nerves is primarily of the pro- inflammatory phenotype}

Since macrophage recruitment (Fig. 1) and phagocytosis (Fig. 2) appeared to be normal between WT and $\mathrm{Cryab}^{-/-}$animals, we then asked if the prolonged presence of $\mathrm{Iba}^{+}$cells in the null animals was related to the phenotype of the macrophages. The reason is, macrophages are influenced by the microenvironment during Wallerian degeneration and can exhibit differing functions due to polarization to specific phenotypes [43]. For instance, pro-inflammatory macrophages are mainly present in the early stages after peripheral nerve injury and function in sterilizing wounds and secreting pro- 

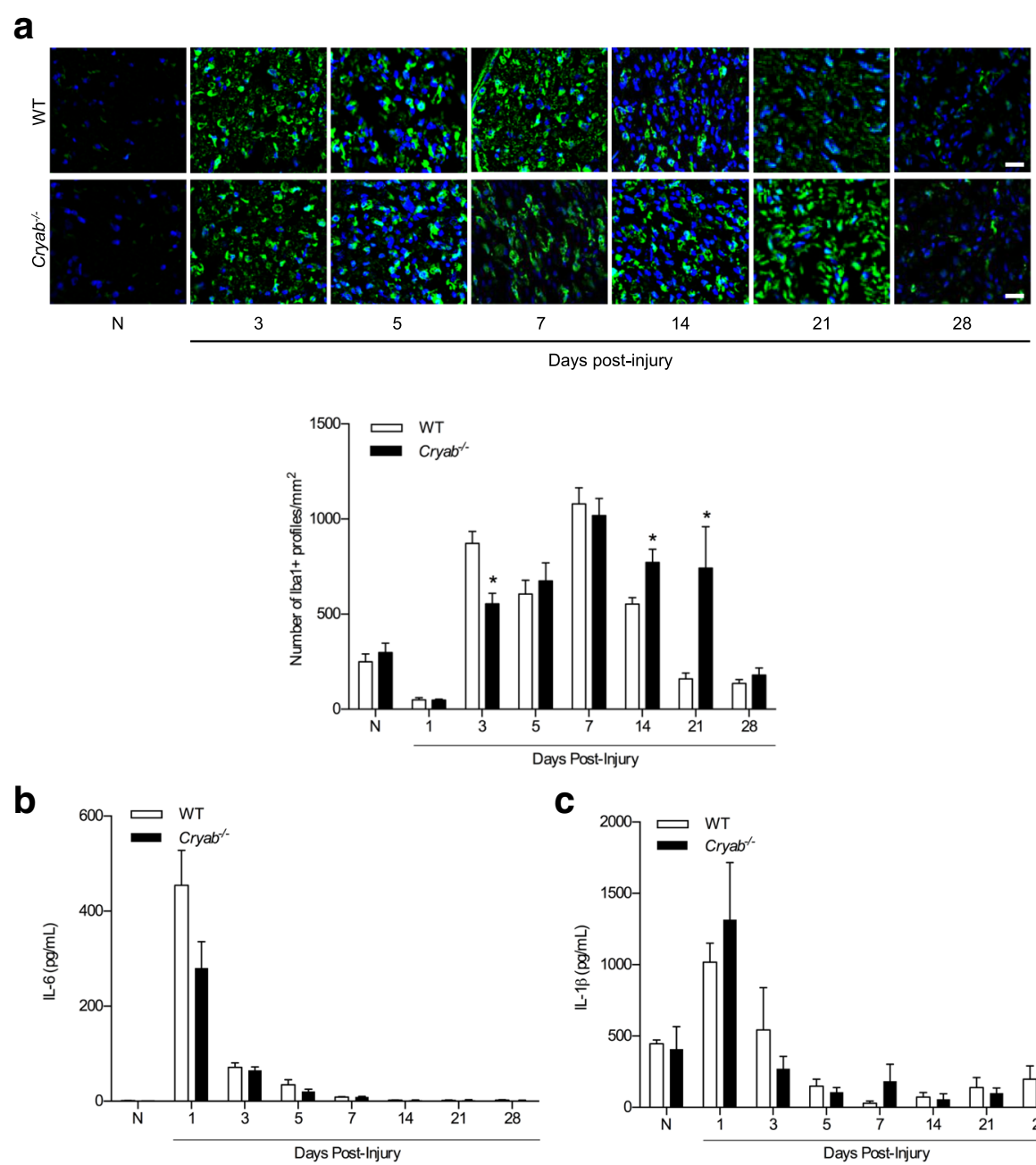

C
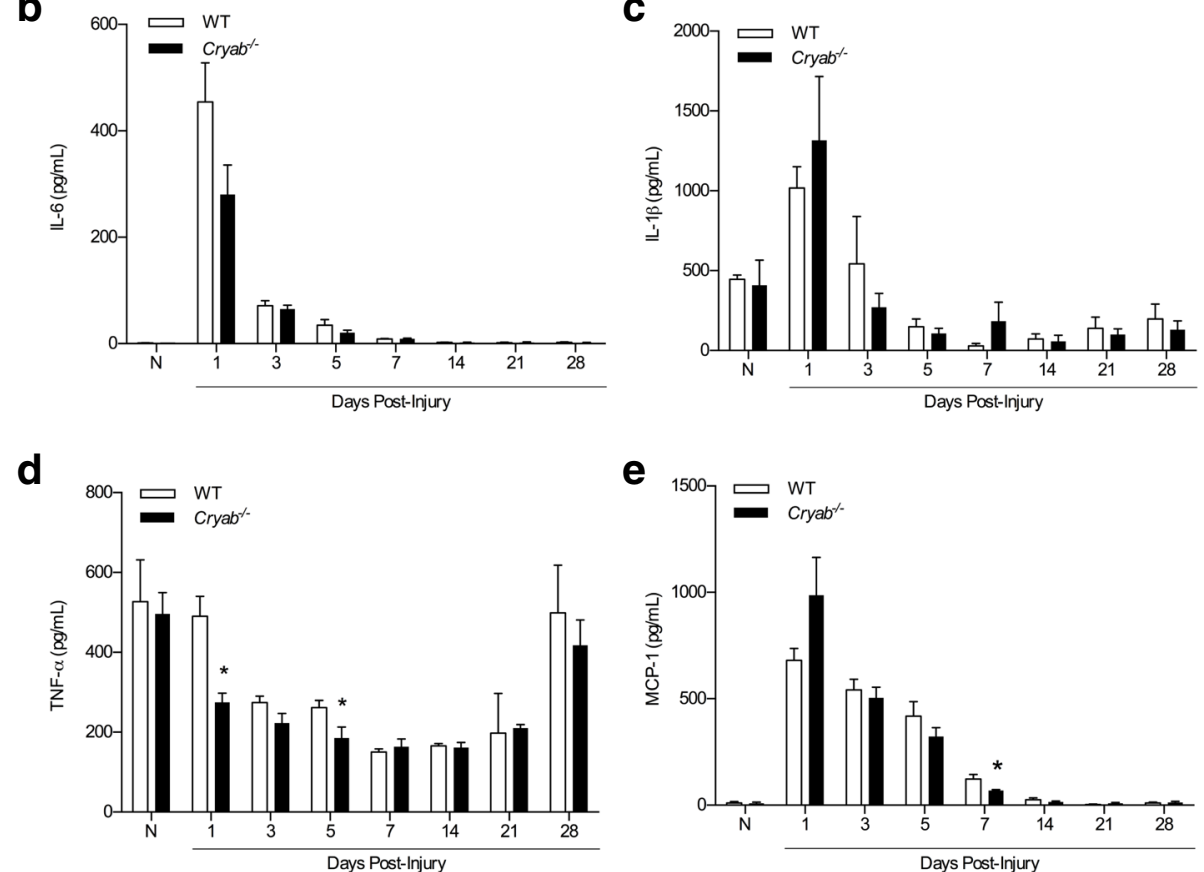

Fig. 1 Number of macrophages and level of cytokines/chemokines in crushed sciatic nerves from WT and Cryab ${ }^{-1-}$ animals. a Representative images and quantification of the number of $\mid \mathrm{ba} 1^{+}$profiles in the sciatic nerves of naïve $(\mathrm{N})$, and $1,3,5,7,14,21$, and 28 days post-crushed WT (white bars) and $\mathrm{Cryab}^{-1-}$ (black bars) animals; representative of 2 experiments, $n=3-5$ animals/group, magnification $=\times 20$, bar $=20 \mu \mathrm{m}$, data represent mean \pm sem, ${ }^{*} p<0.05$ independent $t$-test. $\mathbf{b}$-e Concentration of IL-6 (a), IL-1 $\beta$ (b), TNF-a (c) and MCP-1 (d) in the distal sciatic nerve segments of naïve (N), and 1, 3, 5, 7, 14, 21, and 28 days post-crushed WT (white bars) and Cryab ${ }^{-1-}$ (black bars) mice. Representative of 2 experiments, $n=3-4$ mice/group. Data represent mean $\pm \operatorname{sem},{ }^{*} p<0.05$ independent $t$-test

inflammatory cytokines, proteolytic enzymes, and free radicals $[8,19,44,45]$. Anti-inflammatory macrophages on the other hand, typically balance the proinflammatory cells by downregulating inflammation and initiating wound repair at later stages of recovery $[8,19$, 44-46]. Therefore, we assessed for the number of Iba $1^{+}$ macrophages that was $\mathrm{CD} 16 / 32^{+}$(pro-inflammatory marker) and $\mathrm{CD}^{206^{+}}$(anti-inflammatory marker) [47] in 

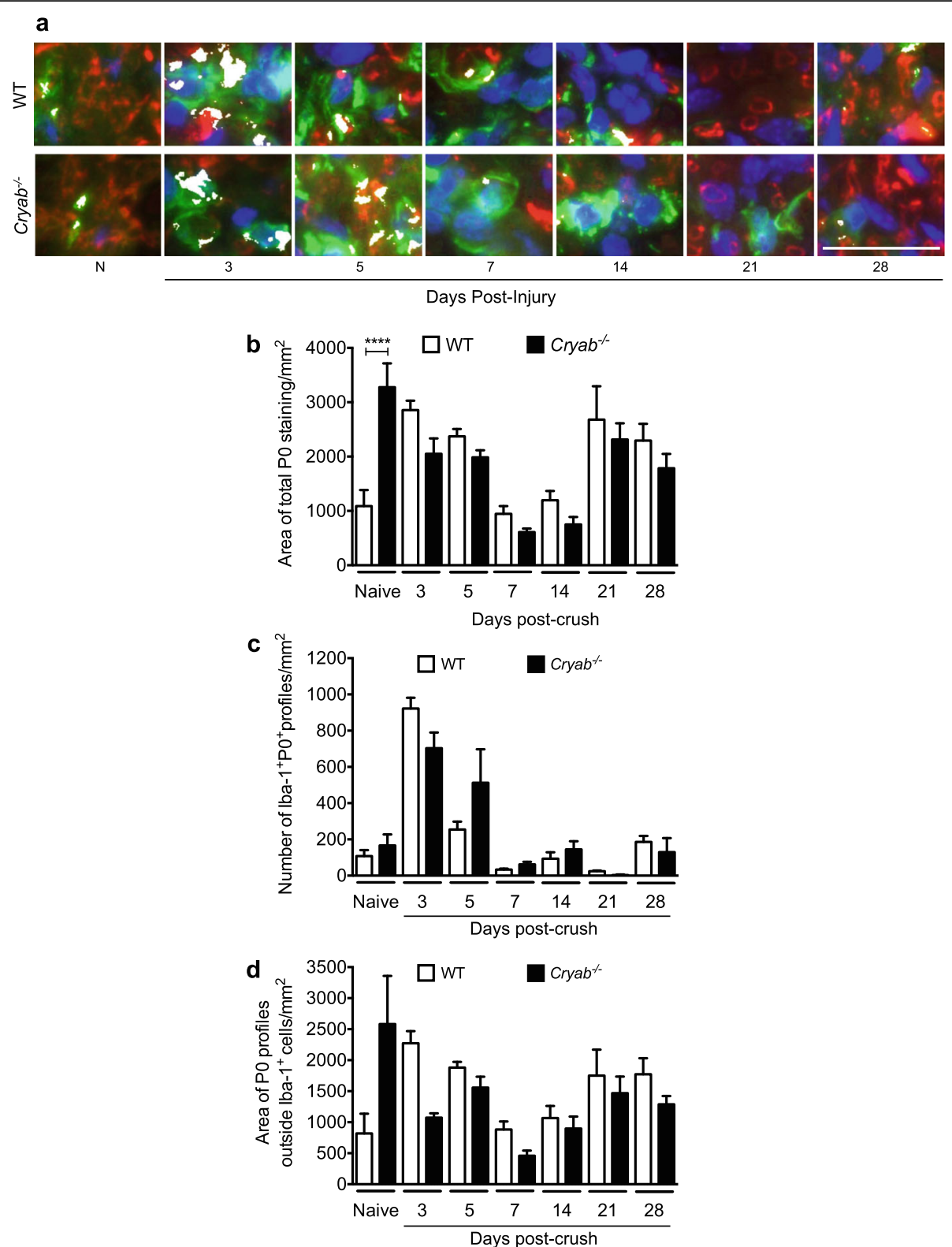

Fig. 2 Presence of $\mathrm{PO}^{+}$myelin within and outside of $\mid \mathrm{ba} 1^{+} \mathrm{DAPl}{ }^{+}$cells. a Representative images of colocalization (white) of $\mathrm{Iba} 1^{+} \mathrm{cells}(\mathrm{green})$ $\mathrm{PO}^{+}$staining (red), and DAPI ${ }^{+}$(blue) in sciatic nerves from naïve and 3,5,7,14, 21, and 28 days post-crushed WT and Cryab ${ }^{-1-}$ mice, bar $=20 \mu \mathrm{m}$. b, c Quantification of the total area of P0 staining (b), number of Iba ${ }^{+}$DAPI ${ }^{+} \mathrm{PO}^{+}$profiles $(\mathbf{c})$, and area of P0 staining outside of Iba ${ }^{+}$DAPI ${ }^{+}$cells (d) in sciatic nerves from naïve and injured WT (white bars) and $\mathrm{Cryab}^{-1-}$ (black bars) animals; $n=3-7$ animals/group, data represent mean \pm sem, ${ }^{*} p<0.05$ independent $t$-test

uninjured and crushed sciatic nerves. For WT animals, the number of $\mathrm{CD} 16 / 32^{+} \mathrm{Iba}^{+} \mathrm{DAPI}^{+}$macrophages increased dramatically within 3 days of injury before reducing to a medium level of inflammation from days 5-28 post-injury as compared to naïve animals (Fig. 3a). For Cryab null nerves, there was also a significant increase in the number of $\mathrm{CD} 16 / 32^{+} \mathrm{Iba1}^{+} \mathrm{DAPI}^{+}$cells at day 3 post-damage that remained elevated from days 5-28 (Fig. 3a). Of particular note, the Cryab ${ }^{-/-} \mathrm{CD} 16 / 32^{+}$ $\mathrm{Iba}^{+} \mathrm{DAPI}^{+}$counts were significantly lower at day 3 and higher at days 14 and 21 post-damage relative to their WT counterparts, similar to what we observed for Iba1 counts only (Fig. 1a). Expression of CD68 (Fig. S1a) and iNOS (Fig. S1b) in $\mathrm{Iba1}^{+}$cells clarified that these cells were in an activated state.

When the ratio of $\mathrm{CD} 16 / 32^{+}$cells to $\mathrm{CD}^{-06^{+}}$cells was analyzed between WT and $\mathrm{Cryab}^{-/-}$nerves at various time points post-injury (Fig. 3e), the ratio for WT nerves remained similar to naïve levels except for a small increase at days 21 and 28. A similar pattern was seen for 


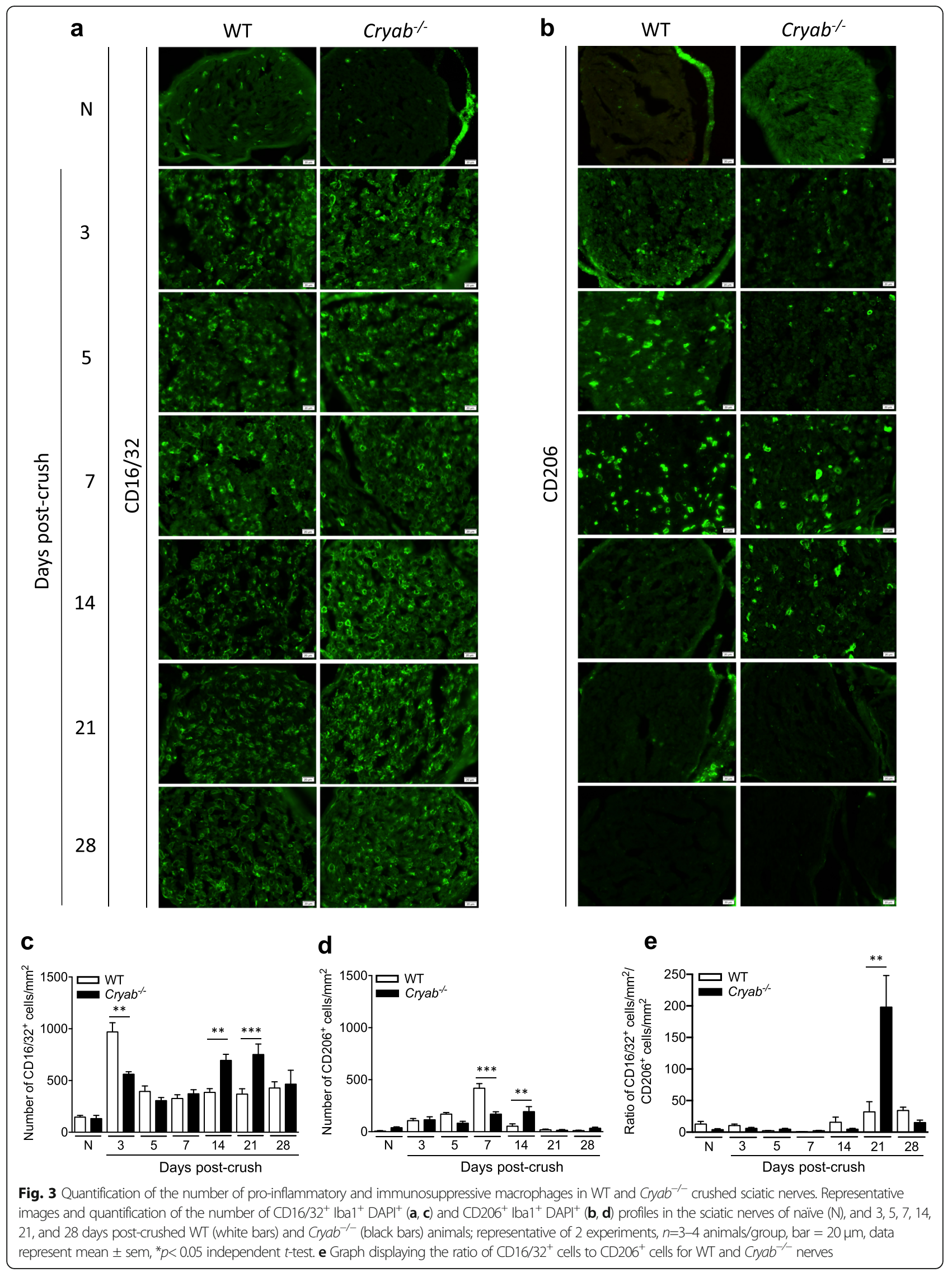


null nerves except for a marked increase in the ratio at day 21 post-injury. In comparing the ratio between genotypes, the values were similar between WT and null nerves from days 3 to 7 after damage. At days 14 and 28 after crush, there was a small reduction in the ratio in null nerves relative to WT. At day 21, this pattern was reversed with a marked increase in the Cryab ${ }^{-/-}$nerves relative to WT animals.

In regard to anti-inflammatory macrophages, although fewer in numbers compared to $\mathrm{CD} 16 / 32^{+}$ $\mathrm{Iba}^{+} \mathrm{DAPI}^{+}$cells, the number of $\mathrm{CD}_{206}{ }^{+} \mathrm{Iba}^{+}$ $\mathrm{DAPI}^{+}$macrophages in injured WT sciatic nerves increased progressively from days 3 to 7 post-injury before dropping markedly to baseline counts from day 14 onwards (Fig. 3b). The Cryab ${ }^{-/-}$mice also displayed an increase in the number of $\mathrm{CD}_{206^{+}} \mathrm{Iba}^{+}$ cells from day 3 after damage but was maintained longer than WT nerves (until day 14 post-crush) before returning to naïve levels at day 21. Significantly fewer and higher numbers of $\mathrm{CD}_{206}{ }^{+} \mathrm{Iba}^{+}$macrophages were noted in the $\mathrm{Cryab}^{-1-}$ nerves at days 7 and 14 respectively compared to WT mice (Fig. $3 \mathrm{~b}$ ). Staining with the immunosuppressive marker, Arg1, verified that some of the Iba $1^{+}$cells were of an antiinflammatory nature (Fig. S1c). Thus altogether, proinflammatory macrophages were present longer in the peripheral nerves of Cryab null animals following PNS crush damage.

\section{CRYAB suppresses pro-inflammatory cytokine levels in peritoneal macrophages}

To try and understand what could be the consequence of prolonged presence of pro-inflammatory macrophages in peripheral nerves after damage, we assessed for the effect of CRYAB on the activation of macrophages. We were specifically interested in pro-inflammatory cytokines since they are involved in neuropathic pain after PNS damage, a pathologic sign that we had previously noted in injured $\mathrm{Cryab}^{-/-}$mice [30]. Because we saw no difference in the cytokine/chemokine levels between WT and $\mathrm{Cryab}^{-/-}$uninjured and damaged nerves at late time points post-injury when enhanced macrophages were noted in the Cryab null mice (Fig. 1), we asked whether the cytokine/chemokine production by null macrophages could have indeed been altered, but because of other cells in the milieu, e.g., Schwann cells and endothelial cells that may be secreting these factors, this resulted in similar overall levels between WT and $\mathrm{Cryab}^{-1-}$ animals. As such, we moved to an in vitro paradigm to assess for cytokine production and costimulatory molecule expression by WT and Cryab ${ }^{-1-}$ macrophages that were grown with or without a CRYAB peptide; this peptide has been shown to possess immunomodulatory functions [35]. Also, because Schwann cells and endothelial cells can also secrete cytokines, the culture system allowed us to focus on the responses specific to macrophages.

Little to no secretion of the pro-inflammatory cytokines IL-1 $\beta$, IL-6, IL-12p40, or TNF- $\alpha$ was detected in macrophages grown in media alone or CRYAB peptide alone groups from either WT or Cryab ${ }^{-/-}$mice (Fig. 4). As expected following LPS stimulation, WT macrophages produced high levels of IL-6, IL-1 $\beta$, IL-12p40, and TNF- $\alpha$ after 24 (Fig. 4 a-d) and 48 h (Fig. 4 e-h) of culturing. Of note, treating LPS-activated peritoneal WT macrophages with the CRYAB peptide significantly reduced the amount of IL-6, IL-1 $\beta$, IL-12p40, and TNF- $\alpha$ secreted at 24 (Fig. $4 \mathrm{a}-\mathrm{d}$ ) and $48 \mathrm{~h}$ (Fig. $4 \mathrm{e}-\mathrm{h}$ ) poststimulation.

Similar to WT macrophages after LPS stimulation, cells from $\mathrm{Cryab}^{-/-}$mice also secreted high levels of IL-6, IL-1 $\beta$, IL-12p40, and TNF- $\alpha$ after 24 (Fig. 4 ad) and $48 \mathrm{~h}$ (Fig. $4 \mathrm{e}-\mathrm{h}$ ) of stimulation. Notably, the amount of IL- 6 and IL-12p40 produced by the LPSactivated $\mathrm{Cryab}^{-/-}$macrophages was significantly higher than WT levels at both time points whereas lower amounts of IL-1 $\beta$ were noted in the Cryab null macrophages with no overall changes seen for TNF- $\alpha$ (Fig. $4 \mathrm{a}-\mathrm{h}$ ). Following CRYAB peptide treatment of $\mathrm{Cryab}^{-/-}$macrophages, we observed a similar effect as that seen for WT cells, where IL-1 $\beta$, IL-12p40, and TNF- $\alpha$ production was reduced after $24 \mathrm{~h}$ (Fig. $4 \mathrm{~b}-\mathrm{d}$ ) and $48 \mathrm{~h}$ (Fig. $4 \mathrm{f}-\mathrm{h}$ ). Interestingly, the difference in cytokine production between WT and $\mathrm{Cryab}^{-1-}$ macrophages was more pronounced after CRYAB peptide application with null macrophages exhibiting higher levels of IL- 6 and TNF- $\alpha$ production after $24 \mathrm{~h}$ (Fig. 4 a, d), and greater levels of IL-6, IL-12p40, and TNF- $\alpha$ secretion after $48 \mathrm{~h}$ (Fig. $4 \mathrm{e}, \mathrm{g}, \mathrm{h}$ ) compared to treated WT macrophages. Taken together, these data suggest that in vitro, CRYAB has the ability to limit the amount of pro-inflammatory cytokines secreted by macrophages and that its removal augments production of such cytokines.

\section{CRYAB does not modulate the machinery for antigen presentation}

In addition to secreting cytokines, activated macrophages act as antigen presenting cells to trigger adaptive immunity and to activate helper T-cells [48] where the co-stimulatory molecules, CD80 and CD86, play a crucial role in initiating and maintaining an immune response through antigen presentation [49]. We therefore assessed if the expression of CD80 and CD86 in peritoneal macrophages was altered by CRYAB. No difference in the expression levels of CD80 and CD86 was observed between WT and Cryab ${ }^{-1-}$ macrophages following stimulation with LPS for $24 \mathrm{~h}$ (Fig. 5a) or $48 \mathrm{~h}$ (Fig. 5b). 


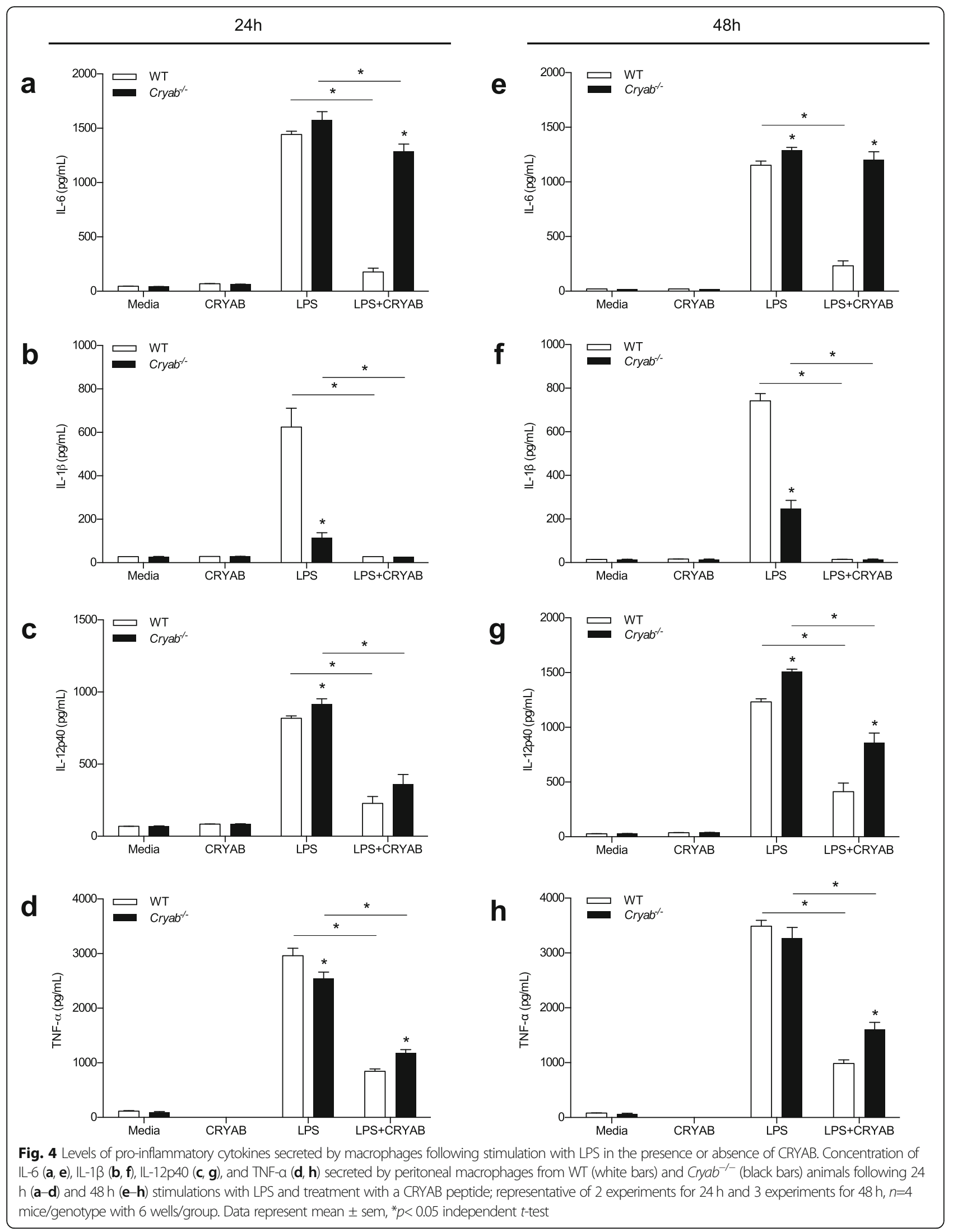




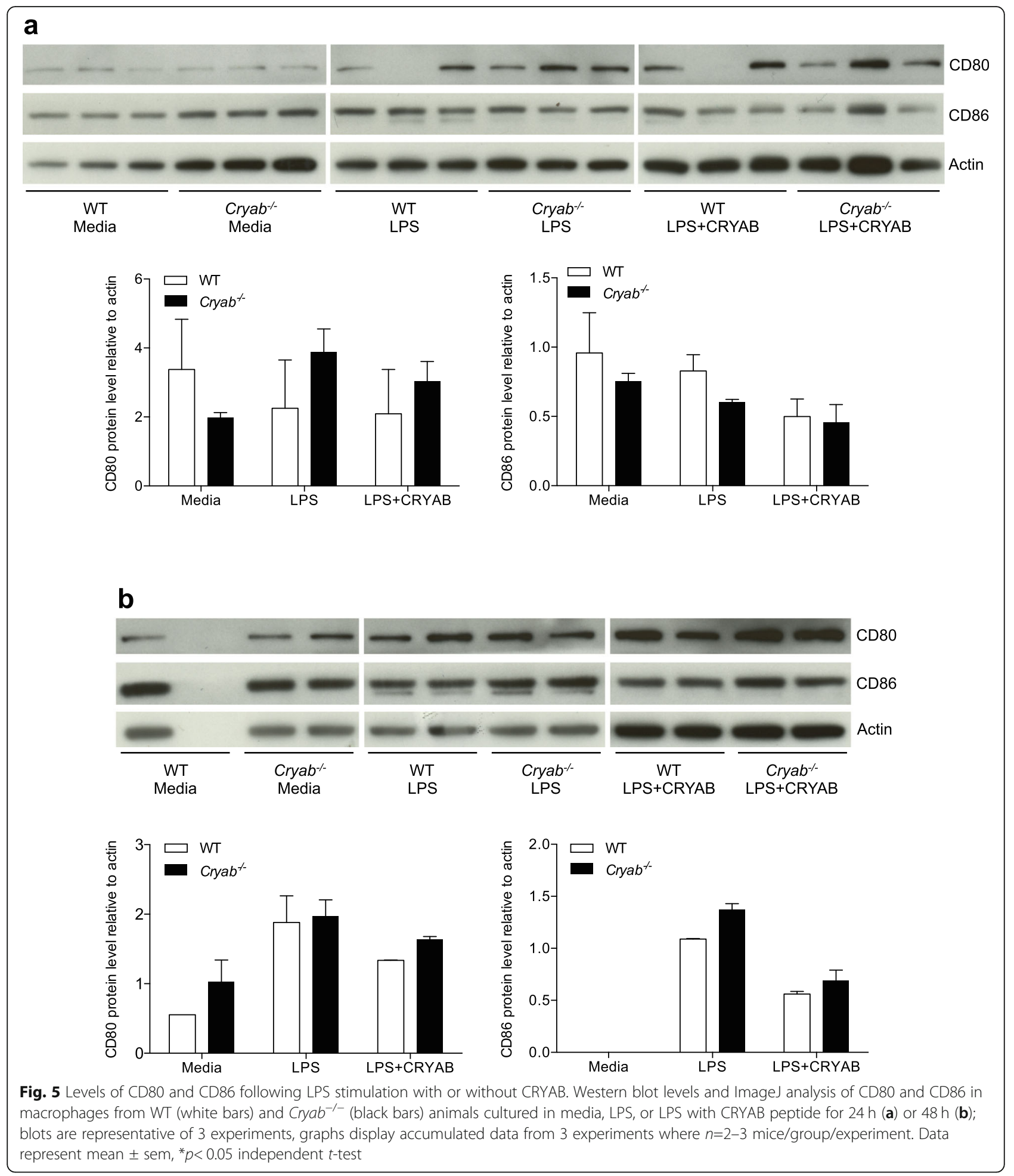

Further, treatment with CRYAB peptide did not alter the levels of CD80 and CD86 after 24h (Fig. 5a) or $48 \mathrm{~h}$ (Fig. 5b) for either WT or Cryab ${ }^{-1-}$ macrophages. These results suggest that CRYAB does not alter the antigen presenting capabilities of macrophages.
Cytokine production by cultured pro-inflammatory polarized peritoneal macrophages is reduced by CRYAB Finally, we interrogated whether the anti-inflammatory effects of CRYAB on macrophage presence in injured sciatic nerves (Fig. 1a) and cytokine production in vitro 
(Fig. 4) depended on the phenotype of the macrophages. To this end, we once again employed the peritoneal macrophage in vitro paradigm. Using a combination of LPS and IFN- $\gamma$, macrophages were polarized towards a pro-inflammatory phenotype as identified by high iNOS and IL-12p40 mRNA expression, and low levels of arginase-1 and IL-10 mRNA (Fig. 6a) while polarization of macrophages toward an anti-inflammatory phenotype was achieved by using a combination of IL-4 and IL-13 (Fig. 6a). These latter cells displayed high amounts of arginase- 1 and IL-10 mRNA and low levels of iNOS and IL-12p40 (Fig. 6a).

Stimulation of WT macrophages for $48 \mathrm{~h}$ with LPS and IFN $-\gamma$ resulted in an increase in the secretion of the pro-inflammatory cytokines IL-6, IL-12p40, and TNF- $\alpha$ (Fig. 6 b, d, e). Activation of Cryab ${ }^{-/-}$macrophages with LPS and IFN- $\gamma$ also resulted in an increase in IL-6, IL12p40, and TNF- $\alpha$ (Fig. 6 b, d, e) with IL-6 and IL12 p40 being produced at much higher levels relative to their WT counterparts (Fig. $6 \mathrm{~b}, \mathrm{~d}$ ). The addition of CRYAB peptide for $48 \mathrm{~h}$ resulted in significant decreases in the secretion levels of IL-6, IL-12p40, and TNF- $\alpha$ in WT, as well as in Cryab null cells (Fig. 6 b, d, e). Of note, the elevated level of cytokines normally produced by $\mathrm{Cryab}^{-1-}$ macrophages as compared to WT cells was maintained for IL-12p40 and TNF- $\alpha$ upon CRYAB peptide treatment (Fig. $6 \mathrm{~d}, \mathrm{e}$ ). These data indicate that CRYAB has the ability to modulate the function of proinflammatory-polarized macrophages by attenuating their secretion of certain pro-inflammatory cytokines.

As expected, anti-inflammatory-polarized macrophages displayed low levels of IL-6, IL-1 $\beta$, IL-12p40, and TNF- $\alpha$ in both WT- and Cryab ${ }^{-1-}$-derived cells, and addition of a CRYAB peptide did not alter the levels of the cytokines (Fig. $6 \mathrm{f}-\mathrm{i}$ ). To determine whether the heat shock protein could influence the anti-inflammatory properties of IL-4/IL-13-polarized macrophages, we assessed for IL-10 production, a typical readout for such polarized cells. The levels of IL-10 were inconsistent over three experiments $(n=4$ replicates/experimental group for each separate experiment) and thus no conclusions could be drawn (data not shown). Taken together, these in vitro data suggest that CRYAB may preferentially modulate pro-inflammatory macrophages by decreasing their secretion of proinflammatory cytokines.

\section{Discussion}

Inflammation constitutes a double-edged sword with respect to nerve regeneration. Many studies have demonstrated the critical role that macrophages play in successful nerve regeneration where depletion of these immune cells before a peripheral nerve injury resulted in reduced myelin debris clearance, loss of neurotrophin synthesis, and decreased axon regeneration and functional recovery [1, 8-10]. However, macrophages also play a vital role in the development of peripheral nerve injury-induced neuropathic pain [13-18], and hyperresponsive pro-inflammatory macrophages can cause tissue damage, while overactive immunosuppressive macrophages can promote fibrosis and exacerbate cytotoxic and allergic reactions [8]. Therefore, macrophage responses must be carefully controlled to harness their beneficial properties that allow for regeneration while preventing their potentially detrimental effects.

Previous studies have highlighted the protective role of CRYAB in decreasing inflammation. The small heat shock protein was shown to reduce $\mathrm{T}$-cell proliferation [33], decrease the secretion of pro-inflammatory cytokines by pathogenic $\mathrm{CD}^{+} \mathrm{T}$-cells $[33,35]$, and protect myoblasts from TNF- $\alpha$-induced cytotoxicity [28]. In the CNS, CRYAB reduced neuroinflammation and motor deficits in an animal model of multiple sclerosis [33], suppressed cytokine production by astrocytes [33, 50], and decreased microglial activation, and recruitment of inflammatory Ly $6 \mathrm{C}^{+}$macrophages following spinal cord injury [32]. Due to its expression in PNS axons and Schwann cells [38-40], we investigated whether CRYAB plays a role in macrophage presence after peripheral nerve injury. We found that $\mathrm{Cryab}^{-/-}$mice had an elevated number of macrophages in injured distal nerve segments at late timepoints post-damage as compared to WT mice. This increase in $\mathrm{Iba}^{+}$macrophages was not due to differential macrophage recruitment following peripheral nerve injury since the number of $\mathrm{Iba}^{+}$cells was comparable between WT and $\mathrm{Cryab}^{-/-}$mice during early time points $(1,3,5$, and 7 days $)$ post-crush. As well, the main cytokines and chemokines responsible for the recruitment of macrophages into the injured site after PNS injury, IL-6, IL-1 $\beta$, TNF- $\alpha$, and MCP-1, displayed similar expression profiles in both WT and Cryab ${ }^{-1-}$ mice indicating that the recruitment of macrophages after PNS injury was not dependent on CRYAB. It also appears that other aspects of Wallerian degeneration such as macrophage phagocytic ability were not responsible for the prolonged presence of the immune cells since no differences were evident between WT and $\mathrm{Cryab}^{-/-}$mice in P0 presence within and outside of $\mathrm{Iba}^{+}$cells. Rather, it appears that the heat shock protein may be involved in resolution of the inflammatory response. In regard to the P0 data, we hypothesize that the gradual increase in P0 area from day 14 onwards in Fig. $2 \mathrm{a}$ and $\mathrm{c}$ is because regenerating axons are being remyelinated after a period of myelin degradation and clearance (days 3-7). In Fig. 2b, we speculate that the number of $\mathrm{P}^{+} \mathrm{Iba}^{+}$counts declines at days 7-21 because myelin is being digested by these cells. Eventually, at day 21, we suggest that all degraded myelin has been 
a
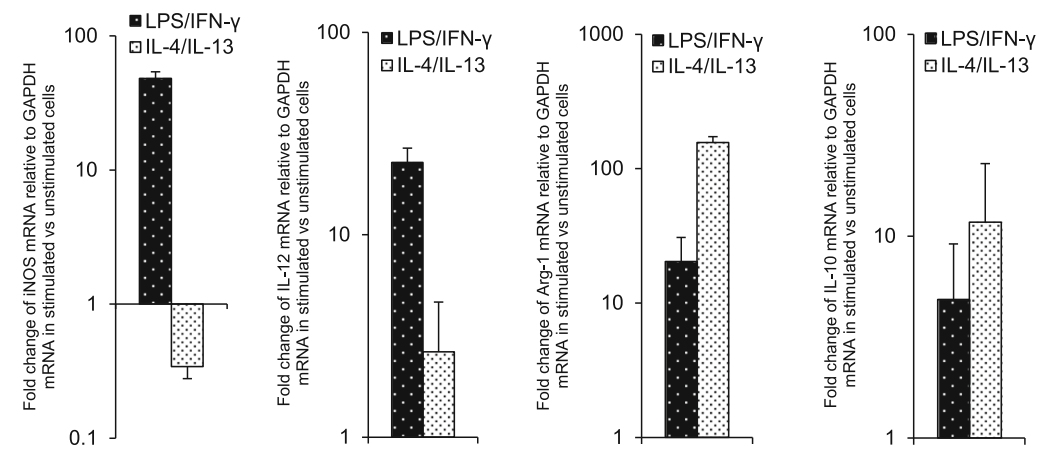

b

C
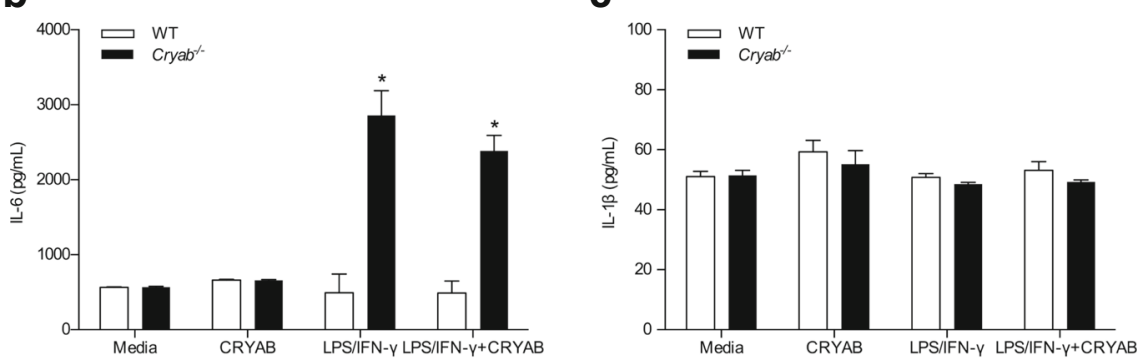

d

e
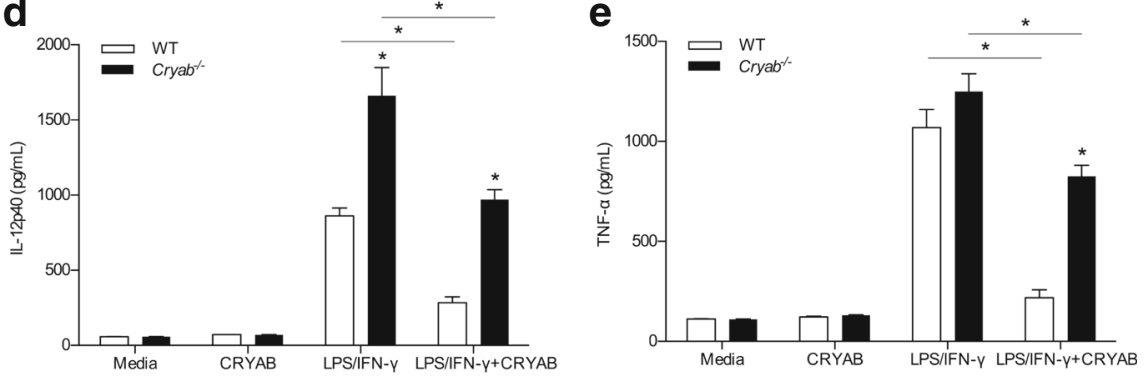

f

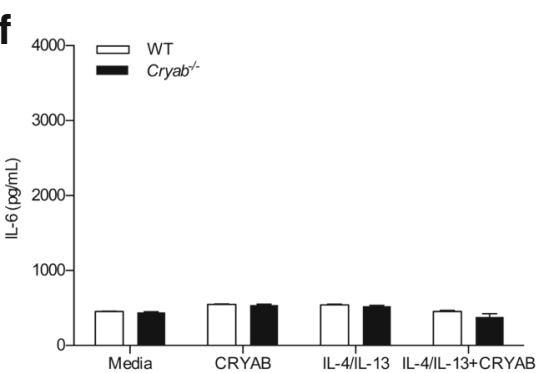

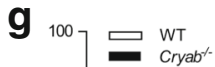

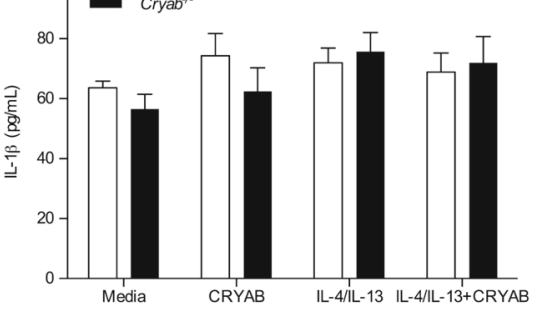

h

i
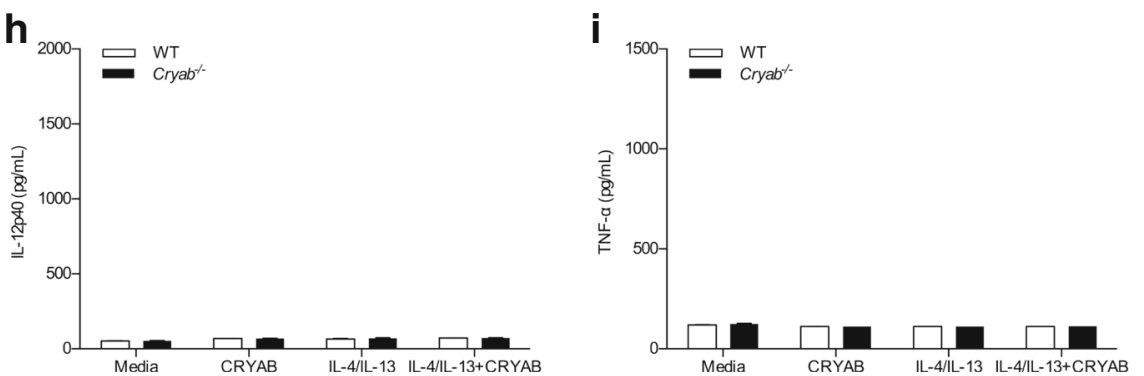

Fig. 6 (See legend on next page.) 
(See figure on previous page.)

Fig. 6 Secretion of cytokines by pro-inflammatory ${ }^{\text {LPS/FN-Y }}$ and anti-inflammatory ${ }^{\mathrm{IL} / \mathrm{L} L-13}$-polarized macrophages following treatment with CRYAB. a mRNA levels of iNOS, IL-12p40, arginase-1, and IL-10 in LPS/IFN- - - and IL-4/L-13-polarized macrophages; representative of 3 experiments, $n=3-4$ wells/group. $\mathbf{b}-\mathbf{i}$

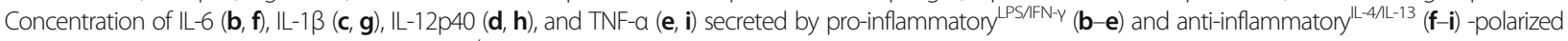
macrophages from WT (white bars) and $\mathrm{Cryab}^{-/-}$(black bars) animals grown for $48 \mathrm{~h}$ in the presence or absence of a CRYAB peptide; representative of 3 experiments, $n=4$ wells/group. Data represent mean \pm sem, ${ }^{*} p<0.05$ independent $t$-test

cleared so $\mathrm{PO}^{+} \mathrm{Iba}^{+}$phagocytosing macrophages are no longer evident/needed in the nerve. Once the nerve is fully regenerated and remyelinated at $\sim$ day 28 , the system goes back to a homeostatic level as in the naïve situation where there is low basal number of $\mathrm{Iba}^{+} \mathrm{P}^{+}$cells.

One mechanism to control inflammatory responses is to reduce immune cell numbers by either inducing apoptosis or stimulating re-entry into the vascular circulation. The rebound of CRYAB expression we previously observed at late time points following PNS crush injury [30] may be involved in this process of immune cell reduction since macrophages remained prominently elevated in the nerves of injured null animals at days 14 and 21 post-crush, a time when their numbers should return to baseline status (Fig. 1a). In alignment with our results, Klopstein et al. [32] observed a decline in $\mathrm{Ly}_{6 \mathrm{C}} \mathrm{C}^{+}$ macrophages in injured spinal cord after treating with recombinant human CRYAB. This would be beneficial since $\mathrm{Ly} 6 \mathrm{C}^{+}$macrophages possess phagocytic, proteolytic, and inflammatory functions and have been associated with many pathological conditions [5]. We did note that although macrophage presence remained high at late time points in Cryab null mice, the levels of cytokines and chemokines were similar to that of WT animals. It is possible that other cell types present in the nerve such as Schwann cells and endothelial cells which can also secrete these factors [19] may be contributing to the overall levels of these inflammatory factors.

Another mechanism to prevent macrophage-mediated damage is to suppress activation of pro-inflammatory cells. We show in vitro that CRYAB has the ability to attenuate the secretion of pro-inflammatory cytokines, where treatment with a CRYAB peptide resulted in significantly reduced secretion of IL-6, IL-1 $\beta$, IL-12p40, and TNF- $\alpha$ following LPS stimulation. Consistent with this observation was that $\mathrm{Cryab}^{-1-}$ cells generally produced higher levels of the pro-inflammatory cytokines compared to WT macrophages even after CRYAB treatment. Our data also indicates that there is selectivity in the actions of CRYAB. The immunosuppressive capabilities of CRYAB appear to be specific to proinflammatory-polarized macrophages and not IL-4/IL13-polarized cells (Fig. 6). As well, the heat shock protein targeted cytokine reduction and not antigen presentation since expression levels of the co-stimulatory molecules CD80 and CD86 were not altered in null macrophages or by application of CRYAB. It should be noted, however, that additional work needs to address if the in vitro data mirrors what occurs in the nerve in vivo. It is also well-known that tissue macrophages vary substantially based on their origin [51] and the peritoneal macrophages we used may not reflect the proliferating endoneurial and infiltrating monocytes/ macrophages present within damaged peripheral nerves. Another caveat is that LPS was used as a general macrophage stimulator but it is possible that other stimulants could produce different responses [19]. Our future studies seek to isolate macrophages from the nerves for phenotypic and activation characterization.

A growing number of studies have implicated proinflammatory-polarized macrophages in driving the neuroinflammation that causes neuropathic pain after peripheral nerve injury, that is, increased sensitivity to thermal stimulation and mechanical allodynia [13-18]. Depletion of macrophages in diabetic rats limited the progression of neuropathic pain by reducing mechanical allodynia [16], and treatment with etifoxine improved locomotion, motor coordination, and sensory functions by decreasing the number of macrophages [11]. We previously showed that injured $\mathrm{Cryab}^{-/-}$mice display heightened sensitivity to thermal and mechanical stimulation [30]. This hypersensitivity could be related to the prolonged presence of proinflammatory macrophages we see here since the time window (days 14 and 21) overlaps with the period of increased sensitivity we had noted in $\mathrm{Cryab}^{-/-}$mice compared to WT counterparts in von Frey Hair examinations (days 8-42 post-crush damage) [30]. Although cytokine and chemokine levels in the nerve were not different between WT and null animals unlike what we saw for macrophages in the in vitro assays we used, it is plausible that the low levels of cytokines could still contribute to pain sensations. However, it should be noted that in addition to macrophages, it is possible that spinal cord microglia may also be involved in the pain signs [52-55].

It is still unclear why macrophage presence was prolonged in the nerves of injured Cryab ${ }^{-1-}$ animals. We tested if a defect in Wallerian degeneration processes such as phagocytic ability of the macrophages may be a factor, but we noted no overall difference in the presence or clearance of $\mathrm{P}^{+}$myelin between the two genotypes. It is possible that factors secreted by other cells in the nerve environment such as Schwann cells and endothelial cells may play a role in maintaining the presence of the immune cells. Interestingly, we had previously 
shown in injured $\mathrm{Cryab}^{-/-}$mice that there may be a defect in de-differentiated Schwann cells being able to differentiate back to a (re)myelinating phenotype. That is, there were fewer $\mathrm{PO}^{+}$Schwann cells at days 14 and 21 post-injury [30] which aligns nicely with our macrophage data here. It is possible that differentiated myelinating Schwann cells secrete or express factor(s) needed for clearance of pro-inflammatory macrophages after peripheral nerve injury. On the flip side, it is also possible that initiation of resolution events such as IL-10 production is delayed in the Cryab null nerves. We did assess for IL-10 levels in injured peripheral nerves but its levels were below the detection range. Similarly, in our in vitro experiments, the levels of IL-10 were inconsistent, and thus, it is unclear whether this immunosuppressive cytokine is playing a meaningful resolution role in our injury model and in vitro system. Our future studies aim to identify any resolution factors and/or macrophage clearance factors.

\section{Conclusions}

Overall, this study shows that CRYAB is associated with the presence of pro-inflammatory macrophages following peripheral nerve injury and that the heat shock protein may reduce production of cytokines in these immune cells when they are polarized to a proinflammatory state. CRYAB could therefore act by decreasing exuberant inflammation after PNS injury.

\section{Supplementary Information}

The online version contains supplementary material available at https://doi. org/10.1186/s12974-021-02108-z.

Additional file 1: Supplementary Fig. S1. Immunostaining of $\mid \mathrm{ba} 1^{+}$ cells with CD68, iNOS and Arg1. Micrographs of $\mathrm{CD}_{6} 8^{+} \mathrm{Iba}^{+} \mathrm{DAPI}^{+}$(a), $\mathrm{iNOS}^{+} \mathrm{Iba}^{+} \mathrm{DAPl}^{+}(\mathrm{b})$ and $\mathrm{Arg}^{+}{ }^{+} \mathrm{bba}^{+} \mathrm{DAPl}^{+}$(c) cells in sciatic nerves at 14 days post-injury in WT and $\mathrm{Cryab}^{-/-}$mice; bar $=20 \mu \mathrm{m}$.

\section{Abbreviations \\ DMEM: Dulbecco's modified eagle media; DTT: Dithiothreitol; EDTA: Ethylenediaminetetraacetic; ELISA: Enzyme-linked immunosorbent assay; G-CSF: Granulocyte-colony-stimulating factor; GM-CSF: Granulocyte- macrophage colony-stimulating factor; IFN: Interferon; IL: Interleukin; IP- 10: Interferon gamma-induced protein 10; KC: Keratinocyte chemoattractant; LIF: Leukemia inhibitory factor; LIX: Lipopolysaccharide-inducible CXC chemokine; LPS: Lipopolysaccharide; MCP: Macrophage chemotactic protein; MIG: Monokine induced by gamma interferon; MIP: Macrophage inflammatory protein; $\mathrm{NaF}$ : Sodium fluoride; $\mathrm{Na}_{3} \mathrm{VO}_{4}$ : Sodium vanadate; OD: Optical density; P0: Protein zero; PNS: Peripheral nervous system; RANT ES: Regulated on activation normal T cell expressed and secreted: SDS: Sodium dodecyl sulfate; TNF: Tumor necrosis factor; Tris-HCL: Tris- hydrocloride; VEGF: Vascular endothelial growth factor; WT: Wildtype}

\section{Acknowledgements}

We thank Dr. Samuel David (McGill University) for providing the iNOS antibody. We also thank the Hotchkiss Brain Institute Advanced Microscopy Platform for use of their facility.

\section{Authors' contributions}

SSO and EML conceived the study and experiments and wrote the manuscript. VH, AF, KMH, KK and TMF assisted with experiments. The author(s) read and approved the final manuscript.

\section{Funding}

This work was supported by the Canadian Institutes of Health Research (PJT166199; PJT-173522), the University of Calgary University Research Grants Committee (1045929), Alberta Innovates (AI), and the University of Calgary Cumming School of Medicine. EML was supported by a studentship from Al and a Hotchkiss Brain Institute Axon Biology and Regeneration Theme studentship support grant.

\section{Availability of data and materials}

All data generated or analyzed during this study are included in this published article.

\section{Ethics approval and consent to participate}

All animal procedures were carried out in accordance with guidelines of the Canadian Council of Animal Care and had received approval by the University of Calgary Animal Resources and Ethics Committee (AC18-0125).

\section{Consent for publication}

Not applicable

\section{Competing interests}

The authors declare no competing interests.

\section{Author details}

${ }^{1}$ Department of Neuroscience, Hotchkiss Brain Institute, University of Calgary, 3330 Hospital Drive N.W., Heritage Medical Research Building, Calgary, Alberta T2N 4N1, Canada. ${ }^{2}$ Department of Clinical Neurosciences, Hotchkiss Brain Institute, University of Calgary, 3330 Hospital Drive N.W., Heritage Medical Research Building, Calgary, Alberta T2N 4N1, Canada. ${ }^{3}$ Department of Cell Biology \& Anatomy, Hotchkiss Brain Institute, University of Calgary, 3330 Hospital Drive N.W., Heritage Medical Research Building, Calgary, Alberta T2N 4N1, Canada.

Received: 22 October 2020 Accepted: 11 February 2021

Published online: 24 March 2021

\section{References}

1. Bisby MA, Chen S. Delayed Wallerian degeneration in sciatic nerves of C57BL/Ola mice is associated with impaired regeneration of sensory axons. Brain Res. 1990;530(1):117-20.

2. Brown MC, Lunn ER, Perry VH. Consequences of slow Wallerian degeneration for regenerating motor and sensory axons. J Neurobiol. 1992: 23(5):521-36.

3. Chen P, Piao X, Bonaldo P. Role of macrophages in Wallerian degeneration and axonal regeneration after peripheral nerve injury. Acta Neuropathol. 2015:130(5):605-18.

4. Dubovy P. Wallerian degeneration and peripheral nerve conditions for both axonal regeneration and neuropathic pain induction. Ann Anat. 2011;193(4): 267-75

5. Arnold L, Henry A, Poron F, Baba-Amer Y, van Rooijen N, Plonquet A, et al. Inflammatory monocytes recruited after skeletal muscle injury switch into antiinflammatory macrophages to support myogenesis. J Exp Med. 2007; 204(5):1057-69.

6. Barrette B, Hebert MA, Filali M, Lafortune K, Vallieres N, Gowing G, et al. Requirement of myeloid cells for axon regeneration. J Neurosci. 2008;28(38): 9363-76.

7. Dubovy $P$, Jancalek R, Kubek T. Role of inflammation and cytokines in peripheral nerve regeneration. Int Rev Neurobiol. 2013;108:173-206.

8. Laskin DL, Sunil VR, Gardner CR, Laskin JD. Macrophages and tissue injury: agents of defense or destruction? Annu Rev Pharmacol Toxicol. 2011;51: 267-88.

9. Mueller M, Leonhard C, Wacker K, Ringelstein EB, Okabe M, Hickey WF, et al. Macrophage response to peripheral nerve injury: the quantitative contribution of resident and hematogenous macrophages. Lab Investig. 2003;83(2):175-85. 
10. Stoll G, Jander S, Myers RR. Degeneration and regeneration of the peripheral nervous system: from Augustus Waller's observations to neuroinflammation. J Peripher Nerv Syst. 2002;7(1):13-27.

11. Girard C, Liu S, Cadepond F, Adams D, Lacroix C, Verleye M, et al. Etifoxine improves peripheral nerve regeneration and functional recovery. Proc Natl Acad Sci U S A. 2008;105(51):20505-10.

12. Echeverry $S, W u$ Y, Zhang J. Selectively reducing cytokine/chemokine expressing macrophages in injured nerves impairs the development of neuropathic pain. Exp Neurol. 2013;240:205-18.

13. Kennedy JM, Zochodne DW. Experimental diabetic neuropathy with spontaneous recovery: is there irreparable damage? Diabetes. 2005;54(3):830-7.

14. Ellis $A$, Bennett DL. Neuroinflammation and the generation of neuropathic pain. Br J Anaesth. 2013;111(1):26-37.

15. Kiguchi N, Maeda T, Kobayashi Y, Fukazawa Y, Kishioka S. Macrophage inflammatory protein-1alpha mediates the development of neuropathic pain following peripheral nerve injury through interleukin-1beta upregulation. Pain. 2010;149(2):305-15.

16. Mert T, Gunay I, Ocal I, Guzel Al, Inal TC, Sencar L, et al. Macrophage depletion delays progression of neuropathic pain in diabetic animals. Naunyn Schmiedeberg's Arch Pharmacol. 2009;379(5):445-52.

17. Ristoiu V. Contribution of macrophages to peripheral neuropathic pain pathogenesis. Life Sci. 2013;93(23):870-81.

18. Rivero A, Mora C, Muros M, Garcia J, Herrera H, Navarro-Gonzalez JF. Pathogenic perspectives for the role of inflammation in diabetic nephropathy. Clin Sci. 2009;116(6):479-92.

19. Gaudet AD, Popovich PG, Ramer MS. Wallerian degeneration: gaining perspective on inflammatory events after peripheral nerve injury. J Neuroinflammation. 2011:8:110

20. Ydens $E$, Amann L, Asselbergh B, Scott CL, Martens $L$, Sichien D, et al. Profiling peripheral nerve macrophages reveals two macrophage subsets with distinct localization, transcriptome and response to injury. Nat Neurosci. 2020;23(5):676-89.

21. Ydens E, Cauwels A, Asselbergh B, Goethals S, Peeraer L, Lornet G, et al. Acute injury in the peripheral nervous system triggers an alternative macrophage response. J Neuroinflammation. 2012;9:176.

22. Bhattacharyya J, Padmanabha Udupa EG, Wang J, Sharma KK. Mini-alphaBcrystallin: a functional element of alphaB-crystallin with chaperone-like activity. Biochemistry. 2006:45(9):3069-76.

23. Derham BK, Harding JJ. Alpha-crystallin as a molecular chaperone. Prog Retin Eye Res. 1999;18(4):463-509.

24. Bova MP, Yaron O, Huang Q, Ding L, Haley DA, Stewart PL, et al. Mutation R120G in alphaB-crystallin, which is linked to a desmin-related myopathy, results in an irregular structure and defective chaperone-like function. Proc Natl Acad Sci U S A. 1999;96(11):6137-42.

25. Acunzo J, Katsogiannou M, Rocchi P. Small heat shock proteins HSP27 (HspB1), alphaB-crystallin (HspB5) and HSP22 (HspB8) as regulators of cell death. Int J Biochem Cell Biol. 2012:44(10):1622-31.

26. Kamradt MC, Chen F, Cryns VL. The small heat shock protein alpha B-crystallin negatively regulates cytochrome c- and caspase-8-dependent activation of caspase3 by inhibiting its autoproteolytic maturation. J Biol Chem. 2001;276(19):16059-63.

27. Mao YW, Liu JP, Xiang H, Li DW. Human alphaA- and alphaB-crystallins bind to Bax and $B c \mid-X(S)$ to sequester their translocation during staurosporineinduced apoptosis. Cell Death Differ. 2004;11(5):512-26.

28. Adhikari AS, Singh BN, Rao KS, Rao CM. alphaB-crystallin, a small heat shock protein, modulates NF-kappaB activity in a phosphorylation-dependent manner and protects muscle myoblasts from TNF-alpha induced cytotoxicity. Biochim Biophys Acta. 2011;1813(8):1532-42.

29. Masilamoni JG, Jesudason EP, Baben B, Jebaraj CE, Dhandayuthapani S, Jayakumar R. Molecular chaperone alpha-crystallin prevents detrimental effects of neuroinflammation. Biochim Biophys Acta. 2006;1762(3):284-93.

30. Lim EMF, Nakanishi ST, Hoghooghi V, Eaton SEA, Palmer AL, Frederick A, et al. AlphaB-crystallin regulates remyelination following peripheral nerve injury PNAS. 2017

31. Hu Z, Li T. HspB5/alphaB-crystallin: properties and current progress in neuropathy. Curr Neurovasc Res. 2008;5(2):143-52.

32. Klopstein A, Santos-Nogueira E, Francos-Quijorna I, Redensek A, David S, Navarro X, et al. Beneficial effects of alphaB-crystallin in spinal cord contusion injury. J Neurosci. 2012;32(42):14478-88.

33. Ousman SS, Tomooka BH, van Noort JM, Wawrousek EF, O'Connor KC, Hafler DA, et al. Protective and therapeutic role for alphaB-crystallin in autoimmune demyelination. Nature. 2007;448(7152):474-9.
34. Oyebamiji Al, Finlay TM, Hough RM, Hoghooghi V, Lim EM, Wong CH, et al. Characterization of migration parameters on peripheral and central nervous system T cells following treatment of experimental allergic encephalomyelitis with CRYAB. J Neuroimmunol. 2013;259(1-2):66-74.

35. Quach QL, Metz LM, Thomas JC, Rothbard JB, Steinman L, Ousman SS. CRYAB modulates the activation of CD4+ T cells from relapsing-remitting multiple sclerosis patients. Mult Scler. 2013;19(14):1867-77.

36. Bakthisaran $\mathrm{R}$, Tangirala R, Rao CM. Small heat shock proteins: role in cellular functions and pathology. Biochim Biophys Acta. 2015;1854(4):291-319.

37. Arac A, Brownell SE, Rothbard JB, Chen C, Ko RM, Pereira MP, et al. Systemic augmentation of alphaB-crystallin provides therapeutic benefit twelve hours post-stroke onset via immune modulation. Proc Natl Acad Sci U S A. 2011; 108(32):13287-92.

38. Iwaki T, Kume-Iwaki A, Goldman JE. Cellular distribution of alpha B-crystallin in non-lenticular tissues. J Histochem Cytochem. 1990:38(1):31-9.

39. Willis D, Li KW, Zheng JQ, Chang JH, Smit AB, Kelly T, et al. Differential transport and local translation of cytoskeletal, injury-response, and neurodegeneration protein mRNAs in axons. J Neurosci. 2005;25(4):778-91.

40. D'Antonio M, Michalovich D, Paterson M, Droggiti A, Woodhoo A, Mirsky R, et al. Gene profiling and bioinformatic analysis of Schwann cell embryonic development and myelination. Glia. 2006;53(5):501-15.

41. Brady JP, Garland DL, Green DE, Tamm ER, Giblin FJ, Wawrousek EF. AlphaBcrystallin in lens development and muscle integrity: a gene knockout approach. Invest Ophthalmol Vis Sci. 2001;42(12):2924-34.

42. Shamash S, Reichert F, Rotshenker S. The cytokine network of Wallerian degeneration: tumor necrosis factor-alpha, interleukin-1alpha, and interleukin-1 beta. J Neurosci. 2002;22(8):3052-60.

43. Kigerl KA, Gensel JC, Ankeny DP, Alexander JK, Donnelly DJ, Popovich PG. Identification of two distinct macrophage subsets with divergent effects causing either neurotoxicity or regeneration in the injured mouse spinal cord. J Neurosci. 2009;29(43):13435-44.

44. Martinez FO, Sica A, Mantovani A, Locati M. Macrophage activation and polarization. Front Biosci. 2008:13:453-61.

45. Porcheray F, Viaud S, Rimaniol AC, Leone C, Samah B, Dereuddre-Bosquet N et al. Macrophage activation switching: an asset for the resolution of inflammation. Clin Exp Immunol. 2005;142(3):481-9.

46. Bhattacharyya J, Shipova EV, Santhoshkumar P, Sharma KK, Ortwerth BJ. Effect of a single AGE modification on the structure and chaperone activity of human alphaB-crystallin. Biochemistry. 2007:46(50):14682-92.

47. Kroner A, Greenhalgh AD, Zarruk JG. Passos Dos Santos R, Gaestel M, David S. TNF and increased intracellular iron alter macrophage polarization to a detrimental M1 phenotype in the injured spinal cord. Neuron. 2014;83(5): 1098-116.

48. Roche PA, Furuta K. The ins and outs of MHC class II-mediated antigen processing and presentation. Nat Rev Immunol. 2015;15(4):203-16.

49. O'Keefe GM, Nguyen VT, Benveniste EN. Regulation and function of class II major histocompatibility complex, CD40, and B7 expression in macrophages and microglia: implications in neurological diseases. J Neuro-Oncol. 2002; 8(6):496-512.

50. Shao W, Zhang SZ, Tang M, Zhang XH, Zhou Z, Yin YQ, et al. Suppression of neuroinflammation by astrocytic dopamine D2 receptors via alphaBcrystallin. Nature. 2013;494(7435):90-4.

51. Ginhoux F, Jung S. Monocytes and macrophages: developmental pathways and tissue homeostasis. Nat Rev Immunol. 2014;14(6):392-404.

52. Chen G, Zhang YQ, Qadri YJ, Serhan CN, Ji RR. Microglia in pain: detrimental and protective roles in pathogenesis and resolution of pain. Neuron. 2018; 100(6):1292-311.

53. Guan ZH, Kuhn JA, Wang XD, Colquitt B, Solorzano C, Vaman S, et al. Injured sensory neuron-derived CSF1 induces microglial proliferation and DAP12-dependent pain. Nat Neurosci. 2016;19(1):94-+.

54. Tsuda M, Mizokoshi A, Shigemoto-Mogami Y, Koizumi S, Inoue K. Activation of p38 mitogen-activated protein kinase in spinal hyperactive microglia contributes to pain hypersensitivity following peripheral nerve injury. Glia. 2004:45(1):89-95.

55. Tozaki-Saitoh H, Tsuda M, Miyata H, Ueda K, Kohsaka S, Inoue K. P2Y(12) receptors in spinal microglia are required for neuropathic pain after peripheral nerve injury. J Neurosci. 2008;28(19):4949-56.

\section{Publisher's Note}

Springer Nature remains neutral with regard to jurisdictional claims in published maps and institutional affiliations. 